\title{
Omphalocoeles: A decade in review
}

\author{
S Singh, MB ChB, FC Plast Surg (SA); A Madaree, FRCS (Eng), FCS (Plast), MMed \\ Department of Plastic Surgery, Inkosi Albert Luthuli Central Hospital and School of Clinical Medicine, College of Health Sciences, Nelson $R$ \\ Mandela School of Medicine, University of KwaZulu-Natal, Durban, South Africa
}

Corresponding author: S Singh (simmi19@icloud.com)

\begin{abstract}
Background. Omphalocoeles are associated with significant morbidity and mortality. The presentation varies greatly and management options differ accordingly. Limited literature exists regarding the varied presentation, associated congenital abnormalities and survival from a South African, or even an African perspective.

Objective. To describe the presentation of omphalocoeles, associated abnormalities and survival rates.

Methods. A retrospective epidemiological chart review of patients referred to the paediatric surgical service with newly diagnosed omphalocoeles, between January 2002 and December 2012. Data retrieved included patient demographics, perinatal history, HIV status, associated abnormalities, size of the omphalocoele, management and outcome.

Results. One hundred and fifty-four patients were diagnosed with an omphalocoele during the study period. There were 117 (75.9\%) associated congenital abnormalities, 64 (41.5\%) minor omphalocoeles (defined as $<5 \mathrm{~cm}$ ) and $66(42.8 \%)$ major omphalocoeles (defined as $>5 \mathrm{~cm}$ ). Eleven patients $(7.1 \%)$ had ruptured omphalocoeles. Beckwith-Wiedemann syndrome was the most commonly associated abnormality (37.6\%), followed by cardiac defects (34.4\%).

Conclusion. Omphalocoeles are associated with high numbers of congenital abnormalities. This further complicates management in a resource-poor environment. There is an increased association with Beckwith-Wiedemann syndrome compared with previous studies. This highlights the need to be vigilant with glucose monitoring and to prevent secondary, avoidable complications.
\end{abstract}

S Afr J Child Health 2016;10(4):211-214. DOI:10.7196/SAJCH.2016.v1014.1149

Omphalocoele is one of the most dramatic presentations in medicine. An omphalocoele is a congenital abnormality characterised by the protrusion of abdominal contents through a full thickness defect, with a thin membrane or sac covering the contents. The condition encompasses variably sized 'simple' abdominal wall defects with no associated abnormalities, to those associated with a spectrum of congenitally acquired abnormalities that include BeckwithWiedemann syndrome, 'omphalocoele, extrophy, imperforate anus, spinal' (OEIS) complex and the pentalogy of Cantrell. Advances in neonatal care have improved the survival of these neonates over the decades; however, their management is not yet standardised to reduce complications and provide a best outcome. The reported incidence is approximately 1 in 3000 to 1 in 10000 live births. ${ }^{[1,2]}$ The incidence of omphalocoeles in South Africa (SA) is unknown owing to the lack of a national database. Omphalocoele is a common presentation to the surgical services at Inkosi Albert Luthuli Central Hospital (IALCH) since it is one of only two facilities in KwaZulu-Natal (KZN) Province with specialised paediatric surgical services capable of managing this condition. IALCH is a tertiary healthcare facility that manages specialist paediatric surgical cases in the public health sector in KZN and the eastern part of Eastern Cape Province. There is currently limited literature from an SA perspective regarding the associated abnormalities, size, management or survival. Survival and outcome are directly linked to the nature of these abnormalities, with complex cardiac defects the leading cause of mortality. It is therefore necessary to define the presentation of these neonates and the challenges that are unique to our environment.

\section{Methods}

A descriptive, retrospective epidemiological chart review of all patients referred to the IALCH department of paediatric surgery was conducted. Patients with a newly diagnosed omphalocoele between January 2002 and December 2012 were included.
Ethical approval was granted by the management of IALCH, the Biomedical Research and Ethics Committee of the University of KZN (BE234/15) and the KZN Department of Health (DoH) (KZ_2016RP3_572) prior to the commencement of this study. Study participants were identified by subject numbers linked to their hospital numbers by means of a password-protected file. All data collected were de-identified for maintenance of confidentiality. Records of all patients with omphalocoele admitted and managed at IALCH between 2002 and 2012 were retrieved from the hospital computer database and analysed. The data included patient demographics, perinatal history, the size of the omphalocoele, any associated congenital anomalies/syndromes, any associated infection (e.g. HIV positivity), as well as overall management and survival. A minor omphalocoele was defined as an abdominal wall defect $<5 \mathrm{~cm}$ in diameter, while a major omphalocoele was defined as one $>5 \mathrm{~cm}$ in diameter. BeckwithWiedemann syndrome was diagnosed clinically with the presence of an omphalocoele, macroglossia and neonatal hypoglycaemia (i.e. two major and one minor criteria) ${ }^{[3]}$ The data were entered on a Microsoft Office Excel 2010 (USA, South Africa) spreadsheet and analysed. Simple descriptive statistics were determined using means, standard deviations (SDs) and modes.

\section{Results}

One hundred and fifty-four patients with omphalocoeles were included in the study series, with an average of 15 patients a year. Ten $(6 \%)$ of the mothers were $<18$ years old. Maternal age of 57 (37.1\%) mothers ranged between 18 and 29 years, $21(13.6 \%)$ ranged between 30 and 39 years, only $4(2.5 \%)$ patients were in the $40-49$-year category, while there were none $>50$ years. The maternal age was not documented in $62(40 \%)$ of the patients. Seventy-five $(48.7 \%)$ patients had a vaginal delivery, whereas 67 (43.5\%) had a caesarean section. The mode of delivery was not documented in $12(7.7 \%)$ patients. Forty-nine $(31.8 \%)$ of the 


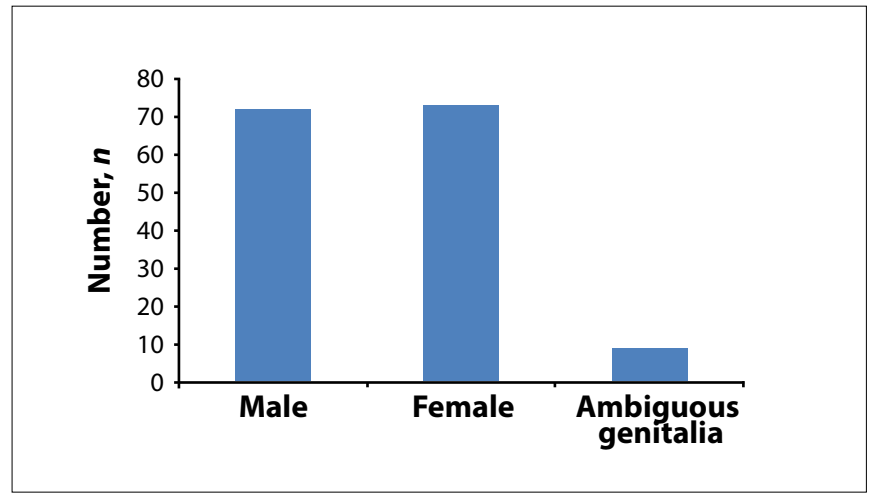

Fig. 1. Gender distribution.

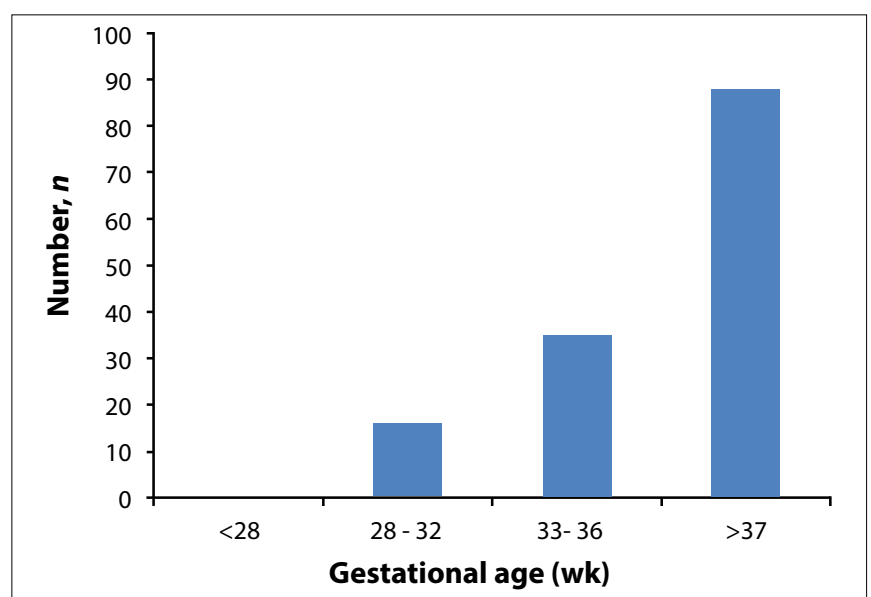

Fig. 2. Gestational age at delivery.

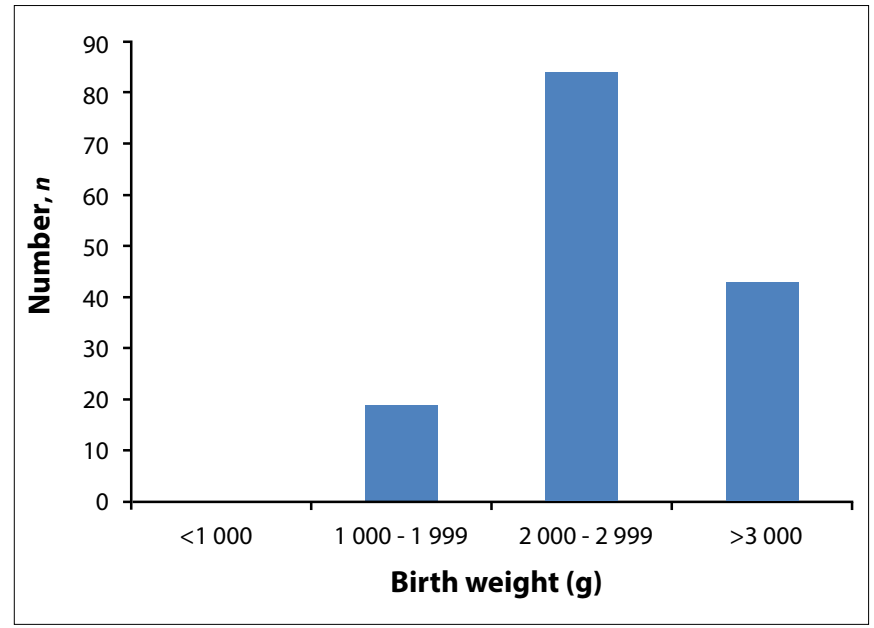

Fig. 3. Birthweight at delivery.

babies were HIV exposed, and for 38 (24.6\%) patients the results were unknown or undocumented. Regarding the patients, there were $73(47.4 \%)$ females, $72(46.7 \%)$ males and 9 (5.8\%) with ambiguous genitalia (Fig. 1). No patients had a gestational age $<28$ weeks. Sixteen $(10.3 \%)$ patients had a gestational age of between 28 and 32 weeks, 35 (22.7\%) were between 33 and 36 weeks, while the majority were delivered at term, 88 (57.1\%) patients (Fig. 2). Three (1.94\%) babies had a birth weight $<1000 \mathrm{~g}, 19$ (12.3\%) were between 1000 and $1999 \mathrm{~g}, 84(54.5 \%)$ between 2000 and $2999 \mathrm{~g}$ and $43(27.9 \%)$ were $>3000$ g (Fig. 3). One hundred and thirty (84.4\%) patients had the size of the omphalocoele documented. In this series, the size of the omphalocoele was documented as

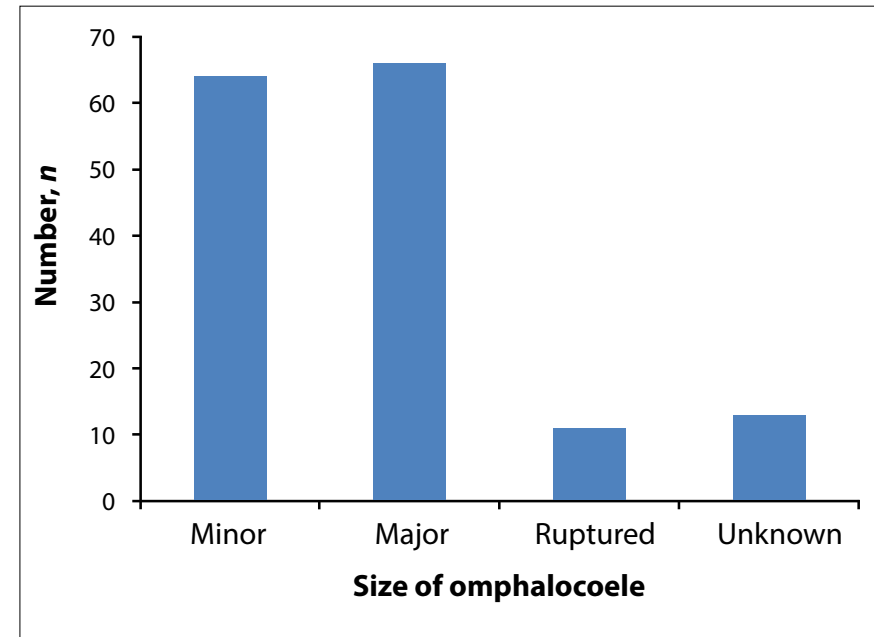

Fig. 4. Size and type of omphalocoele.

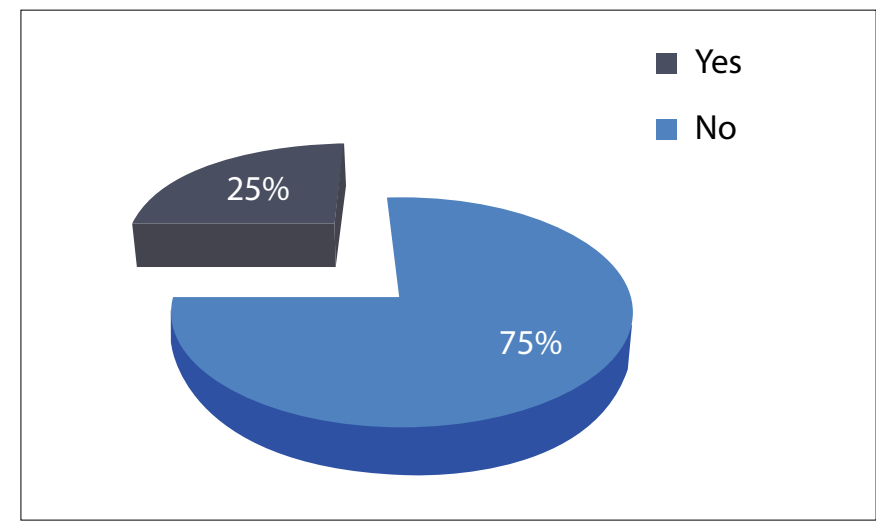

Fig. 5. Distribution of associated congenital anomalies.

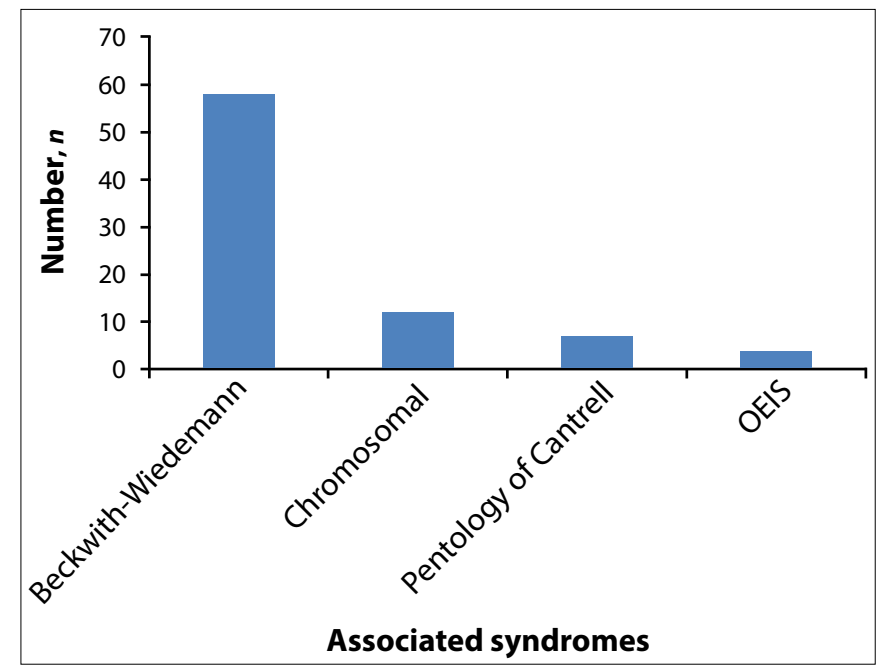

Fig. 6. Types of associated syndromes.

minor, major or with dimensions. Sixty-four $(41.5 \%)$ were minor while $66(42.8 \%)$ were major; overall, $11(7.14 \%)$ were ruptured. The size in 13 (8.44\%) patients was not documented (Fig. 4). The size of the omphalocoele in patients with associated congenital abnormalities was minor in $45(38.4 \%)$ patients and major in $50(42.7 \%)$ patients. In isolated omphalocoeles, 19 (61.2\%) patients had a minor omphalocoele, while $16(41 \%)$ had a major omphalocoele. There were $117(75.9 \%)$ patients with associated congenital abnormalities, while only $39(24.1 \%)$ had isolated 


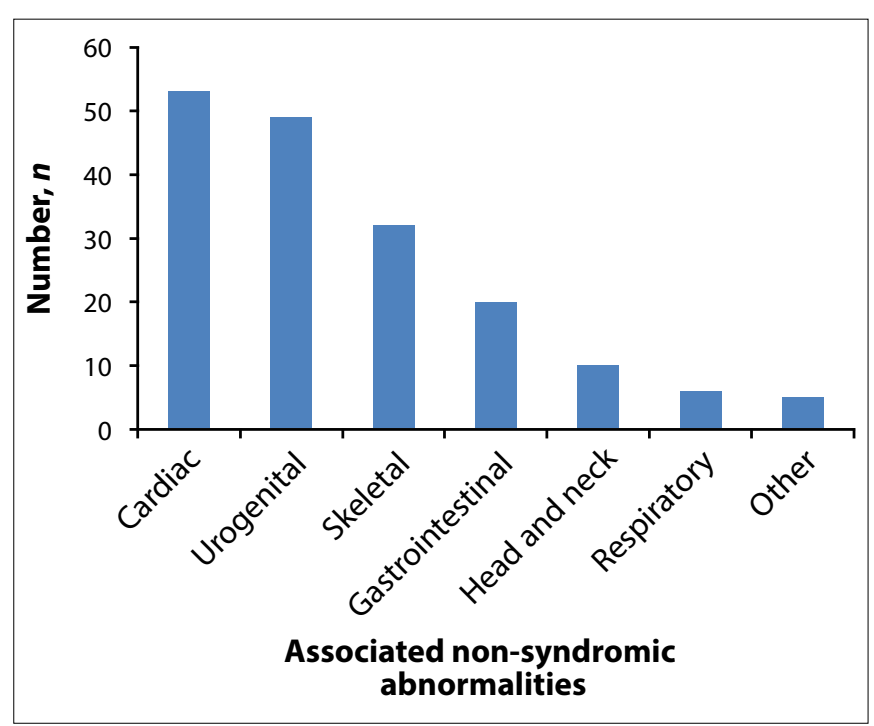

Fig. 7. Non-syndromic congential anomalies identified by organ system.

omphalocoeles (Fig. 5). Beckwith-Wiedemann syndrome had the largest association in this series, with $58(37.6 \%)$ patients. Other syndromes included chromosomal abnormalities, viz. trisomy 18,13 and 21 in $12(7.79 \%)$ patients, pentalogy of Cantrell in $7(4.54 \%)$ and OEIS complex in $4(2.59 \%)$ (Fig. 6). The associated systemic abnormalies in decreasing frequency were cardiac abnormalies in 53 (34.4\%), urogenital 49 (31.8\%), skeletal $32(20.7 \%)$, gastrointestinal tract 20 (12.9\%); head and neck $10(6.49 \%)$; respiratory $6(3.89 \%)$ and $5(3.24 \%)$ other non-specific abnormalities (Fig. 7). Thirty-nine (25.3\%) were described as dysmorphic, which included low-set ears, pre-auricular pits or coarse facial features. The management entailed primary closure in $99(64.2 \%)$ patients, while conservative management with topical silver sulphadiazide (Flamazine, Smith and Nephew SA, SA) applied in $45(29.2 \%)$ patients. The placement of a Gortex patch (Flagstaff, USA) occurred in $6(3.89 \%)$ patients, while amnioinversion was used in $4(2.59 \%)$ and a silo-bag closure in only $2(1.29 \%)$ patients. There were 27 (17.5\%) deaths in this series. Two-thirds of the deaths $(n=18)$ were attributed to the associated congenital abnormality. Six patients (22.2\%) succumbed to sepsis, $2(7.4 \%)$ died as a result of aspiration pneumonia and 1 (3.7\%) had an abdominal compartment syndrome.

\section{Discussion}

Omphalocoele is a congenital, central abdominal wall defect that results in the herniation of the abdominal contents through an umbilical defect with an overlying membrane covering the contents. This study focused on the different presentations of omphalocoeles and the associated congenital abnormalities.

\section{Maternal factors}

McNair et al. ${ }^{[1]}$ reported an association of omphalocoeles with advanced maternal age. In this series, however, $43 \%$ of mothers were $<30$ years and $16 \%$ were $\geq 30$ years. Interestingly, it is known that advanced maternal age ( $>35$ years) is associated with increased chromosomal abnormalities. The presence of chromosomal abnormalities in this study was $<10 \%$. Mann et al. ${ }^{[4]}$ also showed that maternal age $>35$ years is a risk factor for some of the trisomies associated with omphalocoele; maternal age per se does not appear to be an independent risk factor for omphalocoele. Mode of delivery is still controversial. Islam ${ }^{[5]}$ found that there is no study that advocates one method over the other, and numerous reports of safe delivery vaginally. The mode of delivery in this series appears irrelevant as both methods were utilised similarly, with $5 \%$ more vaginal deliveries noted. It is difficult to ascertain why some of the mothers had caesarean section deliveries, as their medical records were kept in the peripheral hospitals.

Sub-Saharan Africa has the largest number of HIV-infected people. Thirty-one percent of patients were exposed to the virus. These patients routinely receive antenatal prophylaxis in the third trimester and undergo polymerase chain reaction testing postnatally. The short- and long-term implications of HIV association with omphalocoeles are yet to be determined.

\section{Neonatal factors}

A study by McNair et al. ${ }^{[1]}$ reported that omphalocoeles occur more frequently in males than in females, at a ratio of $1.5-3: 1$. Mortellaro et al. ${ }^{[2]}$ also reported a male preponderance. In this series, an almost equal number of males and females were found, with $5.8 \%$ of patients having ambiguous genitalia. More than half of the babies were born at term, with only $10 \%$ born before 32 gestational weeks. Hence it follows that most of the babies were $\geq 2 \mathrm{~kg}$ in weight and only $13 \%$ were $<2 \mathrm{~kg}$ in weight. In a study done in Germany, the average birth weight was $2432 \mathrm{~g}$ and gestational age 35.5 weeks. ${ }^{[6]}$ A UK study showed that outcomes have been influenced negatively by birth weight and gestational age, if the birth weight is $<2 \mathrm{~kg}$ or gestational age $<35$ weeks. $^{[7]}$

\section{Omphalocoele size: Minor v. major}

The literature arbitrarily defines a major omphalocoele as $>5 \mathrm{~cm}$ and containing liver or small bowel, and minor as $<5 \mathrm{~cm} \cdot{ }^{[2,5,8]}$ This definition is flawed as it does not consider the size of the baby or the visceroabdominal disproportion. It is, however, the only working definition that helps stratify omphalocoeles. The size of the omphalocoele was fairly equally distributed between the two groups in this study. Groves et al. ${ }^{[9]}$ found that congenital abnormalities were commonly associated with a minor omphalocoele. In his series, he found 39\% of chromosomal abnormalities associated with a minor omphalocoele. In this study, with $75 \%$ associated congenital abnormalities, $42.7 \%$ had a major omphalocoele and $38.4 \%$ had a minor omphalocoele associated with a congenital abnormality. The associated abnormalities did not correlate with the defect size as shown by Groves et al. A minor omphalocoele was more commonly associated with an isolated omphalocoele (61\%). Mann et al. ${ }^{[4]}$ reported that several studies have shown no correlation between defect size and neonatal outcome.

\section{Associated congenital abnormalities}

In this review of one decade, $75 \%$ of patients had other associated abnormalities. This is often associated with increased morbidity and mortality. The literature reports $50-80 \%$ of associated abnormalities. ${ }^{[5,10-12]}$ A UK study found $75 \%$ of exomphalos have associated anomalies, 29\% chromosomal, 30\% non-syndromic multiple congenital anomalies, and recognisable malformation syndrome or pattern in $44 \% .{ }^{[7]}$ Although the associated abnormalities are contributing factors to mortality, the mortality rate in this series was $18 \%$ despite the constraints of a resource-poor environment. The survival rate of isolated omphalocoele is as high as $96 \%$, but this drops significantly in the presence of associated abnormalities. ${ }^{[8]}$ Yazbeck et al $^{[10]}$ found the overall mortality rate to be $37 \%$, while a Canadian study found a mortality rate of $31 \%$.

An interesting finding was the high association of BeckwithWiedemann syndrome. Although this is a known association, the literature reports an incidence of $1-14 \% .^{[1,8,10,11,13]}$ In this series, there were $37.6 \%$ of patients with Beckwith-Wiedemann syndrome. This is often a clinical diagnosis that is easily missed, hence the low reports in the literature. Other syndromes associated with omphalocoele include pentalogy of Cantrell (4.5\%) and 
OEIS complex $(2.5 \%)$. The OEIS complex is rare, occurring in $\sim 1$ in 250000 to 1 in $200000 .^{[14]}$ These syndromes are often incompatible with life. Survival is fraught with morbidities and eventual mortalities. Chromosomal abnormalities, viz. trisomy 13,18 and 21 , were found in $7.7 \%$ of patients. Trisomy 13 was the most common (54.5\%). Chromosomal abnormalities are generally associated with advanced maternal age; in this series, only $2.5 \%$ of patients were $>40$ years. In a Canadian study, $11 \%$ had chromosomal abnormalities. ${ }^{[10]}$ In a New York study, $8 \%$ had chromosomal anomalies with trisomy 13 the most common. ${ }^{[15]}$ Chromosomal abnormalities range from 8 to $40 \%$ in the literature, with trisomy 13 and 18 the most common. ${ }^{[1,11,15]}$ In the nonsyndromic associated abnormalities, cardiac defects were most frequently found $(34.4 \%)$. This is a similar finding to that in the literature $(20-50 \%) .^{[1,2,5,10,11]}$ Tetralogy of Fallot and atrial septal defects were most common, ${ }^{[1]}$ with $50 \%$ having an abnormal cardiac axis. ${ }^{[4]}$ In this series, patent ductus arteriosus was the most common defect $(n=29)$, followed by atrial septal defect $(n=9)$ and ventricular septal defect $(n=7)$. There were three patients with tetralogy of Fallot, two patients with dextrocardia, two patients with coarctation of aorta and one patient with a hypoplastic left heart syndrome. Genitourinary abnormalities were also common in this series (31.8\%), while it is reported as less common in other series where genitourinary, skeletal and facial defects are found in $10-20 \%$ of cases. ${ }^{[1]}$ These include undescended testes, ambiguous genitalia, hydronephrosis, bladder extrophy, cloacal extrophy, patent urachus, polycystic kidneys, hypospadias, bifid scrotum, posterior urethral valves, absent kidney, horseshoe kidney, renal cyst and epispadias.

Skeletal abnormalities were found in $20.7 \%$ of patients. These included, in decreasing order of frequency, club feet, polydactyly, scoliosis, sacral agenesis, hemivertebrae, myelomeningocoele, spina bifida, clinodactyly, syndactyly and absent clavicle. Respiratory abnormalities were only detected in $3.8 \%$ of cases, with pulmonary hypoplasia, pulmonary hypertension, congenital diaphragmatic hernia and bronchomalacia being implicated, as found in the literature. ${ }^{[4]}$

\section{Study limitations}

The study is limited by the unknown number of pregnancy terminations due to antenatally diagnosed omphalocoele and the incidence in spontaneous abortions with this anomaly. Additionally, this was a single-centre study conducted in the public sector, albeit in one of the largest SA provinces and in one of only two referral centres for paediatric surgery in the province.

\section{Conclusion}

Omphalocoele is a congenital, midline abdominal defect carrying a high association with other congenital abnormalities. BeckwithWiedemann syndrome has a much higher association with omphalocoele than has previously been described in the literature. Strict glucose monitoring is vital to prevent secondary complications. Cardiac and genitourinary anomalies are also frequently found. The associated congenital abnormalities prompt a thorough pre-anaesthetic work-up to prevent morbidities and mortalities. Advanced maternal age is not a risk factor for omphalocoele in the local population and there is an equal gender distribution in this series. The size of the omphalocoele does not appear to affect the neonatal outcome. Despite the constraints of a resource-poor environment, the mortality is much lower than quoted in the literature, at only $18 \%$.

Acknowledgement. Thanks to Dr T C Hardcastle for layout and grammar review prior to finalisation of the submission version.

\section{References}

1. McNair C, Hawes J, Urquhart H. Caring for the newborn with an omphalocoele. Neonatal Netw 2006;25(5):319-332. http://dx.doi.org/10.1891/0730 0832.25.5.319

2. Mortellaro VE, St Peter SD, Fike FB, Islam S. Review of the evidence on closure of abdominal wall defects. Pediatr Surg Int 2011;27(4):391-397. http://dx.doi. org/10.1007/s00383-010-2803

3. Weksberg R, Shuman C, Beckwith JB. Beckwith-Wiedemann syndrome. Eur J Hum Genet 2010;18(1):8-14. http://dx.doi.org/10.1038/ejhg.2009.106

4. Mann S, Blinman TA, Wilson R. Prenatal and postnatal management of omphalocele. Prenat Diagn 2008;28(7):626-632. http://dx.doi.org/10.1002/ pd.2008

5. Islam S. Advances in surgery for abdominal wall defects: Gastroschisis and omphalocele. Clin Perinatol 2012;39(2):375-386. http://dx.doi.org/10.1016/J. CLP.2012.04.008

6. Axt R, Quijano F, Boos A, et al. Omphalocele and gastroschisis: Prenatal diagnosis and peripartal management. A case analysis of the years 1989-1997 at the Department of Obstetrics and Gynecology, University of Homburg/Saar. Eur J Obstet Gynecol Reprod Biol 1999;87(1):47-54. http://dx.doi.org/10.1016/ S0301-2115(99)00078-0

7. Marven S, Owen A. Contemporary postnatal surgical management strategies for congenital abdominal wall defects. Semin Pediatr Surg 2008;17(4):222-235. http://dx.doi.org/10.1053/j.sempedsurg.2008.07.002

8. Cohen-Overbeek TE, Tong WH, Hatzmann TR, et al. Omphalocele: Comparison of outcome following prenatal or postnatal diagnosis. Ultrasound Obstet Gynecol 2010;36(6):687-692. http://dx.doi.org/10.1002/uog.7698

9. Groves R, Sunderajan L, Khan AR, et al. Congenital anomalies are commonly associated with exomphalos minor. J Pediatr Surg 41(2):358-361. http://dx.doi. org/10.1016/j.jpedsurg.2005.11.013

10. St-Vil D, Shaw KS, Lallier M, et al. Chromosomal abnormalities in newborns with omphalocoele. J Paediatr Surg 1996;31(6):831-834. http://dx.doi org/10.1016/S0022-3468(96)90146-3

11. Ledbetter DJ. Congenital abdominal wall defects and reconstruction in pediatric surgery: Gastroschisis and omphalocele. Surg Clin North Am 2012;92(3):713727. http://dx.doi.org/10.1016/j.suc.2012.03.010

12. Islam S. Clinical care outcomes in abdominal wall defects. Curr Opin Pediatr 2008;20(3):305-310. http://dx.doi.org/10.1097/MOP.0b013e3282ffdc1e

13. Kilby MD, Lander A, Usher-Somers. Invited commentary: Current issues in obstetrics and genetics exomphalos (omphalocele). Prenatal Diag 1998;18:12831288.

14. Brantberg A, Blaas HG, Haugen SE, Eik-Nes SH. Characteristics and outcome of 90 cases of fetal omphalocele. Ultrasound Obstet Gynecol 2005;26(5):527537. http://dx.doi.org/10.1002/uog.1978

15. Salihu HM, Pierre-Louis BJ, Druschel CM, Kirby RS. Omphalocele and gastroschisis in the State of New York, 1992-1999. Birth Defects Res A Clin Mol Teratol 2003;67(9):630-636. http://dx.doi.org/10.1002/bdra.10113 